\title{
Tradução literária e difusão cultural: entre estética e política
}

\section{Literary translation and cultural diffusion: between aesthetics and politics}

Louis Jolicœur*

louis.jolicoeur@Ili.ulaval.ca

Universidade de Laval

Resumo: A tradução de uma obra literária ultrapassa o âmbito literário do texto fonte. As escolhas feitas dependem, de maneira primordial, das orientações ideológicas, do peso das culturas umas em relação às outras, das decisões de ordem editorial e política, e, enfim, dos estereótipos mantidos entre as culturas. Esses estereótipos não existem no abstrato mas fixam suas raízes nas realidades históricas, para, em seguida, serem alimentados pelos interesses divergentes de um grupo em relação ao outro. Nesse contexto, o tradutor de um romance não cumpre apenas o papel de um passeur entre uma cultura e outra; ele é o veículo de uma intenção mais ou menos articulada, mais ou menos consciente, e se inscreve claramente em uma relação de força, de fraqueza, de eventual luta, entre um grupo cultural e outro. Com o intuito de saber mais sobre esta problemática, é preciso se colocar as seguintes questões: Quem, entre os autores de um país, é traduzido? Quem os traduz e os publica? Para quem eles são traduzidos? Como são traduzidos? Com qual objetivo? O presente artigo examina casos de autores quebequenses na Itália, exemplares sob essa perspectiva.

Palavras-chave: Tradução literária. Difusão cultural. Quebec-Itália.

Abstract: The translation of a literary work reaches well beyond the literary scope of the source text. The choices made depend to a large extent on ideological leanings, the comparative importance of source and target cultures, decisions of an editorial or political nature, and prevailing stereotypes maintained by the two cultures stereotypes that do not exist in a vacuum but that are generally rooted in historical realities and kept alive over time by the divergent interests of one group in relation to the other. In such a context, translators of novels are more than just carriers of messages from one culture to another; they are the vehicle of an intent that has been articulated more or less explicitly and indeed more or less consciously, and they clearly take part in an ongoing relationship of strength, weakness and possibly conflict between two cultures. To gain a better grasp of this issue, we must consider the following questions: Among the authors of a given culture, which ones do we translate? Who translates and publishes these authors? Who are the readers for whom these translations are made? How are these authors translated? Towards what end are they translated? This article examines these questions using the example of Quebecois authors in Italy, a coutry that is exemplary in this regard.

Keywords: Literary translation. Cultural diffusion. Quebec-Italy.

\footnotetext{
* Os direitos desse artigo nos foram gentilmente cedidos pelos Cahiers franco-canadiens de l'Ouest, onde foi originalmente publicado. Ver referência em JOLICOEUR (2010).

"Professor titular do Departamento de Língua, Linguística e Tradução da Universidade de Laval Quebec/CA, além de escritor mundialmente reconhecido.
} 
Se nos parece evidente, a nós tradutores e tradutólogos, que tradução literária e difusão cultural caminham juntas, não é menos verdade que essa equação não é muito aceita fora do círculo de especialistas.

Parece, no entanto, dificilmente contestável, mesmo para aqueles, infelizmente bastante numerosos, para quem a tradução continua uma realidade ainda bem obscura, que a necessidade de dar a conhecer nossa literatura e de levála para além das fronteiras tem como corolário, no geral, o trabalho do tradutor.

Ainda que seja verdade que as dificuldades às quais os tradutores devem enfrentar pareçam, num primeiro momento, estritamente técnicas e linguísticas, não se deve perder de vista que a tradução não existe no abstrato, e que ela não poderá se definir numa perspectiva puramente linguística e absoluta: sabe-se, na verdade, que, quando se trata de cultura, nada ou quase nada existe no absoluto, a fortiori o trabalho do tradutor. Assim, o trabalho do tradutor depende antes de mais nada das orientações ideológicas, do peso das culturas umas em relação às outras, das decisões de ordem editorial e política, e, enfim, dos estereótipos entre as culturas, os quais também não existem no abstrato, mas encontram, ao contrário, no geral, suas raízes nas realidades históricas, para serem em seguida alimentados pelos interesses muitas vezes divergentes de um grupo em relação ao outro. Nesse contexto, o tradutor que traduz um romance não cumpre apenas seu papel de passeur entre uma cultura e outra; ele é o veículo de uma intenção mais ou menos articulada, mais ou menos consciente, e se inscreve claramente em uma relação de força entre um grupo cultural e outro. A tradução é, assim, política, confronto, manipulação, e até mesmo subversão. E quando se pensa na tradução é preciso se questionar sobre: quem se está traduzindo? Para quem? E, claro, o que veremos adiante: como se traduz? Não se pode adiantar que a tradução representa uma dimensão significativa na grande questão da diversidade cultural.

Para ilustrar meu propósito sobre a importância da tradução de uma literatura nacional e do estudo do contexto no qual esta se dá, vejamos a situação dos Estados Unidos. Observemos, primeiramente que, se a produção literária anual da maior parte dos países europeus é constituída, bom ano mau ano, de $20 \%$ a $40 \%$ de traduções, somente 3\% dos títulos publicados em 2008 nos Estados Unidos eram traduções. Mencionemos ainda que se a Itália, a Espanha ou o Quebec compraram nesse mesmo ano os direitos de várias centenas de livros dos Estados Unidos, estes compraram, por outro lado, apenas algumas dezenas de livros italianos, 
espanhóis ou quebequenses, literários ou não. Não é de espantar que, nesse contexto, os jovens da Filadélfia e de Baltimore não saibam muito bem onde fica Florença ou Salamanca, sem falar do Quebec ou de Chicoutimi ${ }^{1}$. O que apreendemos disso é que, salvo alguns grandes nomes, os escritores do mundo continuam totalmente desconhecidos nos principais centros de poder, e isso tem consequências. Eis porque se um tradutor deseja desempenhar um papel mais ativo que aquele que lhe é tradicionalmente confiado, ele pode propor novas vias, textos inéditos, outras culturas a serem descobertas. Ele pode assim contribuir para aproximar os povos e eliminar os preconceitos e os estereótipos pelo melhor meio que tem a sua disposição: o conhecimento do outro.

Se o papel do tradutor é dar a conhecer o outro junto aos seus e vice-e-versa, vemos que a coisa não é simples em um mundo onde o poder se expressa não apenas pelo aparelho econômico mas também pelo peso da cultura dominante e a assimetria dos projetos de tradução. Assim, se aceita-se que o durante de uma cultura dominante e de uma relação assimétrica é a questão dos autores e das culturas periféricas, e que o Quebec é periférico em muitos sentidos (no seio da francofonia, do Canadá, da América), a questão também se coloca de ver como os autores quebequenses se fazem conhecer.

O etnocentrismo não se manifesta apenas pela escolha dos autores a serem traduzidos, mas também pelas técnicas de tradução empregadas, e o mundo anglosaxão não detém o monopólio da "traição" do outro. O etnocentrismo em tradução conheceu seu apogeu na França dos séculos XVIII e XIX, época na qual surge a expressão "les belles infidèles" (MOUNIN, 1955), e quando se traduzia não tanto para se abrir ao outro mas para melhor se fagocitar. É a época em que a tradução dos ingleses equivalia a uma missão civilizadora dos "bárbaros insulares", como diziam alguns e onde, desse modo, se trocava chá por vinho, muito mais apropriado em um romance de amor, e onde se afirmava, sem reservas: "Se Homero lhe incomoda, troque Homero!".

Após essa época pouco gloriosa da história da tradução, o pêndulo continuou oscilando entre os que defendiam a fidelidade a qualquer preço e os adeptos de uma abordagem mais liberal. Temos, por exemplo, do lado dos "fiéis" um Antoine Berman (1984), sem dúvida o melhor representante dessa corrente que ele defende

\footnotetext{
${ }^{1}$ Para maiores detalhes sobre esse tipo de dados, cf. SAPIRO (2008), CÓRDOBA SERRANO (2007), HEILBRON (1999), l'Index Translationum da Unesco etc..
} 
em virtude do respeito incondicional do outro, do apagamento necessário de si diante da estranheza e do estrangeiro, diante de seu atrativo mas também de suas austeridades. Do lado dos "infiéis", temos aqueles que não escondem que um projeto de tradução pode superar, ou até utilizar o outro e se inscrever, por exemplo nas traduções, bastante quebequizadas, das peças de teatro do Quebec hiper nacionalista dos anos 60, em um contexto de luta nacional ${ }^{2}$ (BRISSET, 1990). Sem nos esquecer daqueles que não hesitam em afrancesar um autor como Mordecai Richler, cujas histórias, redigidas em inglês, se passam em Montreal, mas parecem ter perdido tudo dessa realidade quebequense quando traduzidas para o francês "da França".

O debate persiste ainda hoje e nunca encontrará uma resposta definitiva. Isso é positivo e confirma que continuaremos a traduzir e retraduzir os grandes textos a cada meio século em média (não era justamente Borges quem dizia que um texto definitivo decorre da religião ou ... do cansaço?).

No que diz respeito ao debate entre fiéis e infiéis, ou entre sourciers e ciblistes, se se prefere, notemos que aí também nada é simples. Pois, se a abordagem de Berman é a encarnação da abertura ao outro, a técnica que se depreende dela, e que convida o tradutor a violar sua própria língua para dar lugar ao estrangeiro e à sua língua, pode, nesses excessos, levar o leitor a pensar, com toda legitimidade: mas esse autor sabe escrever? O que não contribui para sua entrada na cultura de chegada. Assim, se Lawrence Venuti (1995), outro grande pensador das questões da tradução e da manipulação cultural, tem razão ao estimar que toda tradução é etnocêntrica, há, no entanto, como nuançar isso. Assim, poderíamos propor que, se pensarmos primeiramente no autor e em sua cultura, a tradução terá maior chance de respeitar o outro. Se há realmente desejo de traduzir, de reproduzir o outro para o outro daqui, e, enfim, de reproduzir a ambiguidade do outro (que será sua principal definição ${ }^{3}$ ), ao invés de elucidá-la, chegaremos, talvez, a ser menos etnocêntricos.

Esses exemplos que ilustram as implicações ideológicas da abordagem tradutológica nos permite ir mais além nos desafios sociais e políticos da tradução, e é o que me proponho a fazer me debruçando sobre uma aplicação precisa daquilo

\footnotetext{
${ }^{2}$ Hamlet, trad. Michel Garneau, mudando simplesmente o Lago Saint-Jean! (SHAKESPEARE, 1978).

${ }^{3}$ Umberto Eco trabalha bem essa questão quando explica que a messagem com função estética é antes de mais nada estruturada de maneira ambígua (ECO, 1972).
} 
que implica a prática da tradução literária. Lembremos, inicialmente, o quanto a objetividade é obrigatoriamente ilusória em matéria de cultura, pois para além da beleza e de sua difícil definição, há também o fato de que o belo não é neutro, de que a escolha do outro ao traduzir responde a motivações mais ideológicas que estéticas, e de que $o$ ato de traduzir tem, em geral, como objetivo, para além da desejável abertura ao outro, obter algum "valor agregado" na língua de chegada (aqui também às vezes em um plano mais político que literário), o que não deixa de ter consequência nos debates do momento sobre a diversidade cultural ${ }^{4}$.

Nesse contexto, o lugar da literatura quebequense na Itália é bastante interessante. O presente estudo, efetuado entre 2007-2008, versa sobre as escolhas dos editores italianos no momento de traduzir a literatura do Quebec e visa estudar o olhar que a Itália tem sobre este assim como o impacto dessas traduções sobre o panorama literário italiano. As escolhas dos livros traduzidos, as editoras implicadas e as maneiras de traduzir, tudo isso é, na verdade, bastante revelador. Descobrimos aí o olhar que se tem sobre o outro, incluindo os preconceitos e os estereótipos, caso existam, e, inversamente, o impacto do outro sobre si. As observações apresentadas aqui ainda são preliminares, mas podemos desde já constatar que as escolhas efetuadas em matéria de obras traduzidas parecem sensatas.

Essas escolhas vão, em todo caso, além dos mitos e dos estereótipos habituais ligados ao Quebec e aos quebequenses: ilha francófona em um mar anglófono, desbravadores do Norte, etc.. Podemos também constatar, com certo espanto, que as escolhas são muito representativas do Quebec de hoje, e que os títulos publicados são muito numerosos: mais de uma centena de autores, sendo quase 75 poetas! Constatamos, por outro lado, que os editores são, no geral, conhecidos, mas pequenos, que as tiragens são limitadas, e a distribuição é precária. Esta é uma informação que demonstra interesse, mas que talvez esteja um pouco desconectada do grande público; se este é o caso, é em detrimento, infelizmente, de uma perspectiva da diversidade cultural e da difusão da cultura literária do Quebec.

Além das questões mais técnicas ligadas ao mundo da edição, e que tocam as duas primeiras perguntas mencionadas acima - Quem traduz o quê? Para quem se traduz? -, é necessário se dedicar a outra pergunta: Como as obras

\footnotetext{
${ }^{4} \mathrm{~A}$ esse respeito, é interessante também ver o caso da tradução de romances canadenses na Alemanha. Cf. FLOTOW, 2007.
} 
quebequenses são traduzidas? Não percamos de vista que o como também pode refletir preconceitos e estereótipos. O que observamos nas traduções estudadas no âmbito desta pesquisa é, de início, uma qualidade inquestionável na arte de traduzir, mas também certa hesitação da parte dos tradutores, ligada às vezes a uma má compreensão de certas particularidades linguísticas do francês do Quebec, ou simplesmente causada pela distância geográfica - e cultural - entre o Quebec e a Europa. Em caso de dúvida, freia-se a audácia. E a literatura quebequense parece gerar ainda bastante dúvida! Ora, sem audácia, portanto, sem apropriação da obra, os textos continuam, no geral, mais frios. Isso pode, por outro lado, explicar o confinamento deles a pequenas editoras e a tiragens reduzidas. Mas tudo isso, como as primeiras questões abordadas mais acima, requerem estudo mais aprofundado.

Para entrar no cerne da pesquisa efetuada, e na maneira que essas perguntas ilustram essas balizas de reflexão, vamos ver alguns resultados preliminares sobre a presença da literatura quebequense nas livrarias italianas; em seguida, apresentaremos alguns exemplos do modus operandi dos tradutores italianos da literatura do Quebec.

As listas que seguem foram criadas para sintetizar as informações recolhidas in loco da literatura quebequense na Itália; vale ressaltar que os autores podem ser encontrados em mais de uma das listas que seguem, pois alguns publicaram em mais de um gênero na Itália, por exemplo, romances, coletânea de novelas e de poesia. Os números entre parênteses referem-se aos títulos traduzidos por autor, o asterisco $\left({ }^{*}\right)$ significando que apenas um trecho da obra veio a lume, em geral em uma antologia coletiva (isso se aplica principalmente aos poetas) ${ }^{5}$.

\footnotetext{
${ }^{5}$ Esta lista, assim como as próximas, sintetizam a informação contida em vários documentos e sites, principalmente o documento Traduzioni italiane di opere canadesi francofone (VAUCHER; GRAVILI; MINELLE, 2007), preparado em 2003, e atualizado em 2007, no âmbito dos trabalhos do Centro Interuniversitário de Estudos Quebequenses (CISQ), que reúne pesquisadores de sete universidades italianas. Para mais detalhes sobre o CISQ, e para consultar sua excelente bibliografia, ver o site: http://www2.lingue.unibo.it/cisq/index_flash.htm. Os sites das grandes editoras tais como Marcos y Marcos (http://www.marcosymarcos.com/), Mondadori (www.mondadori.it/) ou Bulzoni (http://www.bulzoni.it/), assim como os das grandes livrarias como a Feltrinelli (www.lafeltrinelli.it/home/) ou Martelli (http://www.libreriamartelli.it/), são igualmente úteis. A brochura Leggete quebecchese - un nuovo mondo da scoprire, elaborada pela delegação do Quebec em Roma, em março de 2007, e que pode ser consultada no site: http://www.mcccf.gouv.qc.ca/ index.php?id=2430, também é muito bem documentada; além disso, contrariamente às demais bibliografias, ela dá um importante espaço ao romance infantojuvenil, muito popular na Itália, como em outros lugares. Também existe uma lista, bem incompleta, no entanto - principalmente no quesito francofonia - proposta pela Embaixada do Canadá em Roma (http://www.dfait-maeci.gc.ca/Canadaeuropa/italy/lista-it.asp). Ver também o site da Associação Italiana de Estudos Canadenses (AISC),
} 
Eis a lista dos romancista/novelistas quebequenses de que pudemos encontrar traduções na Itália, ou cujas traduções são iminentes:

François Barcelo (1), Nadine Bismuth (1), Marie-Claire Blais (2), Elena Botchorichvili (1), Jacques Brault (1), Nicole Brossard (1), Chrystine Brouillet (1), Fulvio Caccia (1), André Carpentier (1), Ying Chen (3), Gil Courtemanche (1), Carole David (1), Sylvie Desrosiers (1), Réjean Ducharme (1), Abla Farhoud (1), Lise Gauvin (1), Claude Gauvreau (1), Anne Hébert (4), Marie-Francine Hébert (1), Louis Hémon (5) ${ }^{6}$, Suzanne Lamy (1), Gilles Marcotte (1), Marco Micone (2), Maryse Pelletier (1), Jacques Poulin (1), Monique Proulx (1), Régine Robin (1), Gabrielle Roy (3), Hector de Saint-Denys Garneau (1), Gaétan Soucy (2), Yves Thériault $(4)^{7}$, Yolande Villemaire (2), Bianca Zagolin (1).

A poesia será tratada de maneira mais sucinta neste estudo, pois trata-se de um gênero cujos modos de difusão, assim como os efeitos em termos de impacto cultural, nos parecem bem diferentes daquilo que pudemos observar com o romance e a novela. Salientaremos, além disso, que na grande maioria dos casos, trata-se essencialmente de poemas isolados publicados em antologias coletivas (em número de 4), como indica o asterisco entre parêntesis, pois, na verdade, apenas 14 poetas dos 73 elencados viram uma ou várias coletâneas completas traduzidas e publicadas. Isso dito, eis em massa os autores que encontramos obras traduzidas, em coletâneas, antologias coletivas ou revistas, na Itália:

Nérée Beauchemin $\left(^{*}\right)$, Michel Beaulieu $\left(^{*}\right)$, Claude Beausoleil $\left({ }^{*}\right)$, Normand de Bellefeuille $\left({ }^{*}\right)$, Jean ÉthierBlais $\left(^{*}\right)$, Marie-Claire Blais $\left({ }^{*}\right)$, Réginald Boisvert $\left({ }^{*}\right)$, Louise Bouchard $\left({ }^{*}\right)$, Jacques Brault $\left({ }^{*}\right)$, André Brochu $\left({ }^{*}\right)$, Nicole Brossard (1), Yves-Gabriel Brunet $\left({ }^{*}\right)$, Arthur Buies $\left({ }^{*}\right)$, Fulvio Caccia $\left({ }^{*}\right)$, Paul Chamberland $\left({ }^{*}\right)$, François Charron $\left({ }^{*}\right)$, Robert Choquette $\left(^{*}\right)$, Cécile Cloutier

no seguinte endereço: http://www.aiscan.it/s. Cf. Fratta (1985), Marcato (1982), Minelle (2004) e ZOPPI (2001).

${ }^{6}$ Observar que todas as cinco traduções de Louis Hémon são do mesmo livro: Maria Chapdelaine.

${ }^{7}$ Como no caso de Hémon, três das quatro traduções de Thériaul são do mesmo livro: Agaguk. 
$\left(^{*}\right)$, Octave Crémazie $\left(^{*}\right)$, Denise Desautels $\left(^{*}\right)$, Roger Des Roches $\left({ }^{*}\right)$, Alfred Desrochers (1), Rosaire Dion-Lévesque $\left({ }^{*}\right)$, Hélène Dorion (1), Raoul Duguay $\left({ }^{*}\right)$, Louis Fréchette $\left({ }^{*}\right)$, François-Xavier Garneau (*), Sylvain Garneau (*), Rhéal Gaudet $\left(^{*}\right)$, Lise Gauvin $\left({ }^{*}\right)$, Claude Gauvreau (*), Roland Giguère (2), Gérald Godin (*), Alain Grandbois (*), Éloi de Grandmont $\left(^{*}\right)$, Daniel Guénette (*), Anne Hébert (2), Gilles Hénault (1), Maurice Henrie $\left({ }^{*}\right)$, François Hertel $\left({ }^{*}\right)$, D. G. Jones $\left({ }^{*}\right)$, Marcel Labine $\left({ }^{*}\right)$, Guy Lafond $\left(^{*}\right)$, Michèle Lalonde $\left(^{*}\right)$, Blanche LamontagneBeauregard $\left({ }^{*}\right)$, Gilbert Langevin $\left({ }^{*}\right)$, Gatien Lapointe $\left({ }^{*}\right)$, PaulMarie Lapointe, Rina Lasnier $\left({ }^{*}\right)$, Félix Leclerc $\left({ }^{*}\right)$, Pamphile Lemay $\left({ }^{*}\right)$, Albert Lozeau $\left({ }^{*}\right)$, Robert Melançon $\left({ }^{*}\right)$, Gaston Miron (5), Paul Morin (1), Émile Nelligan (1), Fernand Ouellette (1), Suzanne Paradis $\left({ }^{*}\right)$, Anthony Phelps (1), Jean-Guy Pilon (1), André Roy $\left({ }^{*}\right)$, Jean Royer $\left({ }^{*}\right)$, Hector de Saint-Denys Garneau (1), Daniel Saint-Germain $\left({ }^{*}\right)$, Michel van Schendel (1), Benjamin Sulte $\left({ }^{*}\right)$, France Théoret $\left({ }^{*}\right)$, Élise Turcotte $\left({ }^{*}\right)$, Marie Uguay $\left({ }^{*}\right)$, Denis Vanier $\left({ }^{*}\right)$, Gilles Vigneault $\left({ }^{*}\right)$, Yolande Villemaire $\left(^{*}\right)$, Josée Yvon $\left(^{*}\right)$.

No que concerne ao teatro, pudemos encontrar nas estantes das principais livrarias italianas peças publicadas pelos seguintes autores, que foram quase todas encenadas na Itália (o primeiro número indica o número de títulos publicados; o segundo indica, caso haja, o número de representações que pudemos levantar):

François Archambault (1-1), Michel-Marc Bouchard (5-2), Pan Bouyoucas (1-0), Normand Chaurette (2-3), Daniel Danis (1-0), René-Daniel Dubois (1-1), Carole Fréchette (1-0), Jean-Louis Gaudet (1-0), Marie Laberge (1-1), Larry Tremblay (1-1), Michel Tremblay (1-1).

Acrescentemos a esta lista o nome de alguns outros dramaturgos cujas peças foram traduzidas e representadas na Itália sem que o texto tenha sido objeto de uma publicação em livro: 
Chantal Bilodeau (1), Frédéric Blanchet (1), Denise Boucher (1), Marie Brassard (1), Hervé Dupuis (1), Claude Gauvreau (1), Suzanne Lebeau (2), Robert Lepage (2), Michel Monty (1), Wajdi Mouawad (1), Hélène Pedneault (1), Patrick Quintal (1), Catherine-Anne Toupin (1), Lise Vaillancourt (1).

No que diz respeito ao ensaio, finalmente, alguns autores também foram traduzidos na Itália:

Bernard Arcand (1), Roland Bourneuf (1), Jacques T. Godbout (1), Réal Ouellet (1), François Paré (1).

A primeira observação que podemos fazer à luz dessa informação é que a literatura quebequense parece muito conhecida na Itália, ao menos a julgar pelo número impressionante de autores recenseados (123). Será necessário verificar o alcance real dos editores em jogo, o que veremos mais adiante, mas a primeira impressão é que há na Itália um interesse real pelos autores do Quebec. Outra conclusão legítima é que o número de poetas e de dramaturgos traduzidos na Itália é, em proporção ao número absoluto, visivelmente mais alto que o de romancistas e novelistas. $\mathrm{Na}$ verdade, os números são isentos de ambiguidade: os autores quebequenses traduzidos na Itália se dividem da seguinte maneira: 23 romancistas/novelistas, 64 poetas, 9 romancistas/novelistas que também são poetas, 22 dramaturgos, 5 ensaístas.

No que diz respeito ao gênero, observamos que os autores quebequenses traduzidos na Itália seguem a seguinte proporção:

\begin{tabular}{|l|r|c|}
\hline Romancistas/novelistas & $(23+9=32)$ & $24 \%$ \\
\hline Poetas & $(64+9=73)$ & $56 \%$ \\
\hline Dramaturgos & $(22)$ & $17 \%$ \\
\hline Ensaístas & $(5)$ & $3 \%$ \\
\hline
\end{tabular}


É interessante comparar esses números com aqueles fornecidos pelo site do Infocentro literário dos escritores quebequenses $\left(L^{\prime} \hat{l} l e\right)^{8}$, preparado pela União das escritoras e escritores quebequenses (UNEO), onde são propostos biobibliografias de quase mil autores quebequenses. Esse site classifica os autores por gênero, certos autores podendo aparecer em mais de uma categoria. Sobre um total de quase mil autores, 567 estão associados ao romance, 227 à novela, 72 ao conto, 392 à poesia, 122 ao teatro, 282 ao ensaio ${ }^{9}$. Podemos dizer, portanto, que os autores se dividem da seguinte maneira (para os fins deste estudo, nós associamos $\mathrm{o}$ conto à novela):

\begin{tabular}{|l|c|c|}
\hline Romancistas/novelistas & $(866)$ & $53,5 \%$ \\
\hline Poetas & $(392)$ & $23 \%$ \\
\hline Dramaturgos & $(122)$ & $7 \%$ \\
\hline Ensaístas & $(282)$ & $16,5 \%$ \\
\hline
\end{tabular}

São 123 o número de autores quebequenses traduzidos na Itália; assim, podemos dizer que em relação aos mil autores recenseados no site L'île, eles representam cerca de $12 \%$.

A proporção de romancistas/novelistas traduzida na Itália em relação ao número total de romancistas/novelistas recenseados pelo site L'île é, por outro lado, de $3,7 \%$. Uma proporção muito menor que os $12 \%$ correspondentes ao número de autores quebequenses traduzidos na Itália de maneira geral.

Quanto à proporção de poetas traduzidos na Itália em relação ao número total de poetas recenseados pelo site L'île, ela é de $19 \%$. Na verdade, grosso modo, se os poetas são duas vezes menos numerosos que os romancistas/novelistas repertoriados no site L'île, eles são, ao contrário, duas vezes mais numerosos que os romancistas/novelistas a serem traduzidos na Itália. Constatação espantosa, mas

\footnotetext{
${ }^{8}$ Ver site L'île: http://www.litterature.org.

${ }^{9}$ Outros gêneros são igualmente recenseados pelo site L'île, mas eles não são considerados pelo presente estudo. A título informativo, mencionemos que, além dos gêneros citados acima, encontramos ainda: infantojuvenil (148), relato (129), quadrinhos (3), biografia (20). Precisemos ainda que por autor quebequense compreendemos os autores francófonos, membros da União das escritoras e escritores quebequenses (UNEO), morando, em geral, no Quebec. Essa definição é, com certeza, restritiva, mas não é pior que outras e permite utilizar os dados da UNEQ a título comparativo.
} 
que não deve se eclipsar pelo fato de que a maioria dos poetas são publicados em antologias coletivas.

A proporção de dramaturgos traduzidos na Itália em relação ao número total de dramaturgos recenseados pelo site L'île é de 18\%. Um número igualmente admirável, mas que deve ser considerado com precaução, pois apenas a metade dos dramaturgos teve suas obras publicadas. Mesmo assim, em matéria de visibilidade da cultura quebequense, trata-se de um número impressionante.

Enfim, a proporção de ensaístas traduzidos na Itália em relação ao número total de ensaístas recenseados pelo site de L'île é de $2 \%$.

De acordo com uma perspectiva que chamaremos de endógena, poderíamos atribuir essa disparidade ao fato de que a poesia seja mais valorizada na Itália que no Quebec (ainda que essa afirmação seja discutível): os italianos afirmariam, assim, na escolha de suas traduções, os gostos literários que são próprios da cultura deles e privilegiariam um gênero, importando a poesia em proporções mais importantes que àquela da cultura onde é produzida. Segundo uma perspectiva que chamaremos de exógena, podemos explicar essa disparidade dizendo que, em seu interesse pela cultura quebequense, a Itália tem uma predileção pela poesia.

Difícil dizer. Poderíamos também colocar a ênfase sobre o próprio gênero, e dizer que a poesia se prestaria mais à tradução. Outra afirmação discutível, concordamos. Também poderíamos pensar que esses resultados constituem apenas o reflexo de uma tendência em favor da poesia de um pequeno grupo de amigos do Quebec e de tradutores especializados, reagrupados, por exemplo, no seio do Centro Interuniversitário de Estudos Quebequenses (CISQ). Mas a grande diversidade dos grupos em jogo - governos, universidades, tradutores, editoras etc. -, torna essa hipótese pouco provável. Nos resta uma explicação mais prosaica: bom número de poetas traduzido viu apenas alguns de seus poemas traduzidos, em antologias coletivas, principalmente. Para se ter um quadro mais claro, seria necessário recensear não apenas o número de autores traduzidos, mas também o número de títulos publicados e a tiragem. Este é um trabalho ao qual seria necessário se dedicar. Quanto aos títulos traduzidos na Itália, os números variam consideravelmente em relação aos números que acabamos de ver por autor, pois, como mencionamos acima, certo número de romancistas/novelistas tem mais de um livro traduzido, ou mais de uma tradução de um mesmo livro; enquanto certo número de poetas é publicado apenas em antologias coletivas. 
Vejamos os números correspondentes aos títulos publicados, para um total de 90 publicações:

\begin{tabular}{|l|c|c|}
\hline $\begin{array}{l}\text { Romances e coletâneas } \\
\text { de novelas }\end{array}$ & $(49)$ & $55 \%$ \\
\hline $\begin{array}{l}\text { Coletâneas de poesia (21 } \\
\text { individuais, 4 coletivas) }\end{array}$ & $(25)$ & $27 \%$ \\
\hline Peças de teatro & $(12)$ & $13 \%$ \\
\hline Ensaios & $(4)$ & $5 \%$ \\
\hline
\end{tabular}

A relação entre romances/coletâneas de novelas e coletâneas de poesia é, como vemos, completamente inversa em relação àquela observada anteriormente entre romancistas/novelistas e poetas. Isso dá novamente ao romance e à novela um lugar mais importante que aquele pensado inicialmente, mas o número impressionante de poetas traduzidos na Itália é um fato incontestável e muito significativo, que seria necessário confrontar com a situação presente em outras esferas linguísticas, a espanhola por exemplo ${ }^{10}$.

Quaisquer que sejam as conclusões que escolhemos tirar dessa observação, é necessário notar a importância do lugar da poesia na literatura quebequense traduzida na Itália e, mesmo não fornecendo uma explicação definitiva, tentar ver o impacto sobre a imagem do Quebec veiculada no país receptor dessas traduções.

Antes de tentar analisar essa imagem, notemos outros elementos importantes. Na verdade, é admirável que os romancistas, além de Anne Hébert, Louis Hémon, Suzanne Lamy, Gabrielle Roy e Yves Thériault, sejam contemporâneos. Entre esses, recenseamos certo número de autores de romances infantojuvenis (ou ao menos cuja obra traduzida na Itália pertence a esse gênero), principalmente Chrystine Brouillet e Sylvie Desrosiers.

Sobre esse ponto, os romancistas se opõem aos poetas, uma vez que bom número deles é menos representativo da realidade contemporânea, aquela que

\footnotetext{
${ }^{10} \mathrm{O}$ importante lugar ocupado pela poesia quebequense na América hispânica é também admirável. Ver a esse respeito o estudo de STRATFORD (2008). Deve-se observar, no entanto, como explica esse estudo, que as numerosas traduções de poetas do Quebec em espanhol devem-se, em grande parte, aos contatos entre os Écrits des forges [companhia sem fins lucrativos que publica exclusivamente poesia - N.T.] e algumas editoras mexicanas, e que a distribuição de coletâneas não é muito abrangente. Além disso, seria preciso comparar esta realidade àquela da tradução de romances quebequenses em espanhol.
} 
poderíamos estimar que contribuísse para esboçar a imagem atual da sociedade quebequense na Itália por meio da tradução de sua literatura. Na verdade, um grande número de poetas é do século XIX: Nérée Beauchemin, Arthur Buies, Octave Crémazie, Louis Fréchette, François-Xavier Garneau e Pamphile Lemay; ou nasceram no início do século XX: Robert Choquette, Alfred Desrochers, Rosaire Dion-Lévesque, Alain Grandbois, Anne Hébert, Blanche Lamontagne-Beauregard, Rina Lasnier, Albert Lozeau, Émile Nelligan e Hector de Saint-Denys Garneau.

Além dos números, seria necessário se debruçar sobre questões como a tiragem, o ano de publicação, a importância das editoras, a qualidade das traduções etc. Esta é uma tarefa considerável, que falta ser feita. Nesse sentido, notemos, inicialmente, que as primeiras traduções de obras literárias quebequenses na Itália foram feitas ao longo dos anos 50; foi depois do final dos anos de 1990 que se observa um verdadeiro entusiasmo pela literatura do Quebec no país de Moravia. Em particular após 2003, ano em que o Canadá foi convidado de honra da Feira internacional do livro de Turim, na qual foram apresentadas uma dezena de traduções italianas de romances quebequenses (é interessante observar que durante esse mesmo ano de 2003, o Quebec foi o convidado de honra da Feira internacional do livro de Guadalajara, a mais importante feira do livro do mundo hispânico). Vale ressaltar também que, se as traduções na origem eram, com frequência, objeto das pequenas editoras, certos autores quebequenses, principalmente romancistas, são agora publicados pelas grandes editoras italianas, tais como Marcos y Marcos (François Barcelo, Gaétan Soucy), Feltrinelli (Gil Courtemanche), Voland (Nadine Bismuth), Bompiani (Marie-Claire Blais), Baldini \& Castaldi (Ying Chen), Longanesi (Réjean Ducharme), Mondadori (Anne Hébert), Bulzoni (Roland Giguère, Gilles Hénault, Paul-Marie Lapointe, Gaston Miron, Émile Neligan, Fernand Ouelette, Jean-Guy Pilon). Esta é a grande distinção que é preciso fazer entre romance/novela e poesia. De fato, se os poetas, como vimos, são mais numerosos a serem traduzidos que os romancistas, os novelistas e os dramaturgos, as obras deles, no geral publicadas por pequenas editoras, são pouco difundidas (exceção aos poetas publicados pela editora Bulzoni).

Notemos igualmente a importância da editora Hortus Conclusus e de sua coleção Betula destinada ao Quebec (Jacques Poulin), assim como aquela das Edições Sinnos e de sua coleção Laurentide, também destinada ao Quebec (André Carpentier, Anne Hébert, Suzanne Lamy, Gabrielle Roy, Yves Thériault). 
Sem dúvida, o presente estudo é preliminar e demanda ainda muitas pesquisas. Esperando poder dizer mais sobre a situação da literatura quebequense na Itália, podemos, no entanto, de maneira geral, observar certas tendências interessantes, em particular naquilo que diz respeito à tradução dos romances quebequenses contemporâneos, os mais representativos da realidade do Quebec de hoje, e que parecem estar cada vez mais disponíveis para o público italiano. Esperando que assim se possa apresentar uma imagem do Quebec que corresponda à imagem de nós mesmos que desejamos ver refletida no estrangeiro.

Como já dissemos, a presença da literatura quebequense nas livrarias é uma das modalidades pelas quais se manifesta a importância da tradução nas trocas culturais, uma vez que ela demonstra a escolha dos autores a traduzir (o que se traduz e para quem se traduz), mas nos falta examinar ainda outro componente essencial desta problemática: como se traduz. É, portanto, interessante nos demorarmos um pouco sobre o modus operandi dos tradutores italianos de literatura quebequense.

As traduções estudadas, uma bela fatura em seu conjunto, e efetuada por tradutores renomados, revelam, no entanto, como já evocamos anteriormente, certa hesitação, que parece ligada, às vezes, a uma má compreensão de certos termos, em geral familiares ou regionais, ou simplesmente culturalmente "estranhos", em particular nos romances recentes.

Os exemplos mais representativos dessa tendência são, sem dúvida, as coletâneas de novelas Les gens fidèles ne font pas les nouveles de Nadine Bismuth (2001), o romance La petite fille qui aimait trop les allumettes de Gaétan Soucy (1998) e o romance Volkwagen blues de Jacques Poulin (1984). É interessante observar que se tratam, no conjunto, de sucessos de livraria no Quebec e que são todos escritos em um francês relativamente próximo ao da norma internacional. Os quebecismos são pouco numerosos nesses livros (salvo, talvez, em certas novelas de Nadine Bismuth), limitando-se aos diálogos e, de maneira geral, são fáceis de serem decodificados pelo contexto.

Além disso, as dificuldades de tradução referem-se principalmente ao nível de familiaridade de certas expressões que propriamente ao sentido. Os tradutores cometem erros de compreensão nesses casos, mas, no geral, hesitam em encontrar expressões com o mesmo nível de familiaridade, ainda que haja em italiano termos equivalentes. Eis alguns exemplos: 
$\mathbb{B}_{\text {disme }} \mathcal{A}$

Nadine BISMUTH:

1. "Elle a la switch libido coincée à off."

"L'interruttore della libido ce l'ha bloccato sull'off."11

Retrotradução literal: "Elle a l'interrupteur de la libido bloquée à off."

Percebe-se uma perda clara do nível de familiaridade que poderia ter sido evitado utilizando um termo mais forte e mais próximo da gíria como interruttore.

2. "Pousse mais pousse égal."

"Non ti sembra di esagerare?" 12

Retrotradução literal: "Tu ne crois pas que tu exagères?"

Aqui ainda, expressões muito frequentes como "ma dai", seguidas de uma interjeição, teriam permitido uma melhor aproximação do efeito original.

3. "Il est tellement cheap, ce nettoyeur."

"Costa davvero poco quella lavanderia." 13

Retrotradução literal: "Il coûte vraiment peu ce nettoyeur."

O sentido quebequense de cheap [pessoa avarenta - N.T.] não foi compreendido.

4. "Non, mais c'est épeurant en titi."

"No, ma un pò fa paura." 14

Retrotradução literal: "Non, mais ça fait un peu peur."

Aqui, novamente, o sentido quebequense de titi [muito - N.T.] foi mal compreendido e identificado como um diminutivo ao invés de um superlativo.

\section{Gaétan SOUCY:}

5. "Je savais qu'il me fallait me bombarder au plus sacrant dans cet ouvrage." (SOUCY, 1998, p. 102)

"Sapevo che dovevo catapultarmi alla disgraziata in quel lavoro." (SOUCY, 2003, p. 110)

\footnotetext{
11 "Cheap love" (BISMUTH, 2001, p. 55); "Amore a buon mercato" (BISMUTH, 2003, p. 35).

12 "Le brunch"( BISMUTH, 2001, p. 64); "Il brunch" (BISMUTH, 2003, p. 40).

13 "La tradition"(BISMUTH, 2001, p. 196); "La tradizione" (BISMUTH, 2003, p. 129).

14 "La tradition”(BISMUTH, 2001, p. 205); "La tradizione” (BISMUTH, 2003, p. 136).
} 
$\mathbb{B}_{\mathrm{disse} \mathfrak{A}}$

ISSN: 1983 2435

Retrotradução literal: "Je savais que je devais me catapulter tristement dans ce travail."

O sentido quebequense de au plus sacrant [o mais rápido - N.T.] não foi compreendido.

6. "Quant aux oies blanches [...], nous allions les voir [...] sacrer le camp" (SOUCY, 1998, p. 179)

"Quanto alle oche bianche [...], andavamo per vederle consacrare il campo." (SOUCY, 2003, p. 180)

Retrotradução literal: “..., nous allions les voir consacrer le champ.”

O sentido de sacrer le camp [ir embora, partir - N.T.] não foi apreendido.

Jacques POULIN:

7. "Du pâté chinois !" (POULIN, 1984, p. 155)

“Un paté cinese !" (POULIN, 2000, p. 144)

A tradução literal aqui dá a entender que realmente se trata de um patê chinês... [prato do Quebec feito de uma camada de carne moída, uma camada de milho e uma camada de purê de batatas - N.T.].

Em caso de dúvida, freia-se a audácia, dizíamos. O que arrisca, certamente, afetar o efeito geral de um texto e, consequentemente, de sua recepção. Vários outros exemplos foram elencados durante nossa pesquisa, mas que não podemos apresentar aqui por falta de espaço, e indicam que nas traduções italianas de obras literárias quebequenses, os desvios ligados ao nível de familiaridade são tão numerosos quanto os erros de sentido. A solução para essas dificuldades só pode vir de um melhor conhecimento da realidade cultural e linguística quebequense, assim como de uma multiplicação das ferramentas lexicográficas on-line. A esse respeito, não há dúvida de que o trabalho feito hoje é admirável. No entanto, ainda há muito o que fazer, principalmente no plano da visibilidade da cultura quebequense no estrangeiro, da informação dada às editoras, da publicidade, da distribuição dos livros etc.. Depois, cabe assegurar que a literatura quebequense encontre e seduza os tradutores, a ponto de que eles desejarão, de verdade, se apropriar dela e fazê-la reviver na língua do outro. Uma missão difícil, mas que pode apoiar-se sobre uma grande rede de pessoas e de instituições que, tanto no Quebec 
quanto na península italiana, ou no mundo, se dedica à difusão e a um melhor conhecimento da cultura quebequense no estrangeiro. No geral, eles têm poucos recursos, mas muita boa vontade. É preciso lhes dar todo o apoio possível. Mencionemos principalmente: a Delegação Geral do Quebec em Roma (que finalmente recebeu seu status de delegação oficial), o Centro Interuniversitário de Estudos Quebequenses (CISQ), a Associação Italiana de Estudos Canadenses (AlÉC), os vários centros de pesquisa das universidades do Quebec que se dedicam à difusão da cultura, da literatura e do léxico do Quebec, a Associação internacional dos estudos quebequenses (AlÉQ), a União das Escritoras e Escritores Quebequenses (UNEQ) etc..

Faltam muitas coisas a serem exploradas. Nós advertimos no início que se tratava de resultados preliminares, e a situação evolui rapidamente. Esperamos, no entanto, ter apresentado a tradução como uma ferramenta que pode contribuir para a diversidade cultural e para uma melhor compreensão da visão que se pode ter de si no estrangeiro. A tradução vista não como um instrumento da mundialização, mas como uma ferramenta crítica que permite refletir sobre isso.

\section{Referências}

BERMAN, A. L'épreuve de l'étranger: culture et traduction dans l'Allemagne romantique: Herder, Goethe, Schlegel, Novalis, Humboldt, Schlelermacher, Hölderlin. Paris: Gallimard, 1984, 311 p.

BISMUTH, N. Les gens fidèles ne font pas les nouvelles. Montreal: Boréal, 2001, 226 p.

$155 \mathrm{p}$. . La fedeltà non fa notizia. Trad. Cristiano Felice. Roma: Voland, 2003,

BRISSET, A. Sociocritique de la traduction. Longueuil: Le Préambule, 1990, 347 p.

CÓRDOBA SERRANO, M. S. La fiction québécoise traduite en Espagne: une question de réseaux. Meta, 2007, v. 52, n. 4, p. 763-792.

ECO, U. La structure absente. Trad. Uccio Esposito Torriguani. Paris: Mercure de France, 1972, $446 \mathrm{p}$.

FLOTOW, L. Revealing the "soul of which nation?": Translated literature as cultural diplomacy. In: ST-PIERRE, P.; KAR, P. C. (dir.). Translation: Reflections, Refractions, Transformations. Amsterdam: John Benjamins Press, 2007, p. 187-200. 
FRATTA, C. Traduzioni italiane di testi letterari quebecchesi. /l Veltro, 1985, v. 19, n. 3-4, p. 303-312.

HEILBRON, J. Towards a Sociology of Translation: Book Translations as a Cultural World-System. European Journal of Social Theory, 1999, v. 2, n. 4, p. 429-444.

JOLICOEUR, L. Traduction littéraire et diffusion culturelle: entre esthétique et politique. Cahiers franco-canadiens de l'Ouest, 2010, v. 22, n. 2, p. 177-196. Disponível em: <http://www.erudit.org/revue/cfco/2010/v22/n2/1009122ar.pdfz. Acesso em 28 dez 2016.

MARCATO, F. Présence de la littérature québécoise en Italie. In: CAMERLAIN, L. et al. (dir.) Lectures européennes de la littérature québécoise: actes du Colloque international de Montréal, avril 1981, Montréal: Leméac, 1982, p. 45-59.

MINELLE, C. Traduzioni italiane di opere quebecchesi (1990-2003): "un défrichement qui se fait”. Francofonia, 2004, n. 46, p. 33-47.

MOUNIN, G. Les belles infidèles. Paris: Cahiers du Sud, 1955, 159 p.

NOVELLI, N. Traductions italiennes de Maria Chapdelaine. In: CAMERLAIN, L. et al. (dir.) Lectures européennes de la littérature québécoise: actes du Colloque international de Montréal, avril 1981, Montréal: Leméac, 1982, p. 64-74.

POULIN, J. Volkswagen blues. Montréal, Québec: Amérique, 1984, 290 p.

Rosa Baldi.

Volkswagen blues. Roma: Hortus Conclusus, 2000, 304 p. Trad. Maria

SAPIRO, G. (dir.) Translatio: le marché de la traduction en France à l'heure de la mondialisation. Paris: CNRS Éditions, 2008, 427 p.

SHAKESPEARE, W. Hamlet. Trad. Michel Garneau.Montreal: VLB Éditeur, 1978, $152 \mathrm{p}$.

SOUCY, G. La petite fille qui aimait trop les allumettes. Trad. Francesco Bruno. Montreal: Boréal, 1998, $179 \mathrm{p}$.

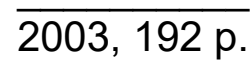

La bambina che amava troppo i fiammiferi. Milão: Marcos y Marcos,

STRATFORD, M. La identidad quebequense traducida al español: modos de difusión de la poesía quebequense en el mundo hispánico. In: GRANERO DE GOENAGA, A. M. et al. (Dir.). La Traducción: Hacia un encuentro de lenguas y culturas. Córdoba: Comunicarte, 2008, p. 143-166.

VAUCHER GRAVILI, A.; MINELLE, C. Traduzioni italiane di opere canadesi francofone. Quebec: Association internationale des études québécoises, 2007, n.p. 
$\mathbb{B}_{\text {disise }} \mathcal{A}$

ISSN: 1983 2435

VENUTI, L. The Translator's Invisibility: A History of Translation. Londres: Routledge, 1995, $353 \mathrm{p}$.

ZOPPI, S. L'émergence des études québécoises en Italie. Globe: revue internationale d'études québécoises, 2001, v. 4, n' 2, p. 229-237.

Traduzido por Katia Aily Franco de Camargo - kafcamargo@gmail.com

Recebido em 02/01/2017

Aceito em 15/01/2017

Publicado em 17/01/2017 